\title{
Conceptualizing Smart Sustainable Cities: Crossing Visions and Utilizing Resources in Africa
}

\author{
Dr. Ahmed Al-Gindy ${ }^{1}$ \\ Dr. Ziad Elkhatib ${ }^{4}$ \\ Faculty of Engineering \\ Canadian University Dubai \\ Dubai, United Arab Emirates
}

\author{
Eng. Aya Al-Chikh Omar ${ }^{2}$ \\ Faculty of Engineering and \\ Technology \\ Aldar University College \\ Dubai, United Arab Emirates
}

\author{
Eng. Mariam Aerabe ${ }^{3}$ \\ Faculty of Engineering and \\ Technology \\ Aldar University College \\ Dubai, United Arab Emirates
}

\begin{abstract}
Recent advancements in technologies enabled the development of smart cities to be more effective and possible. Smart cities depend on intelligent systems, artificial intelligence, the internet of things, control system, and many more advanced technologies. Sustainability challenges and problems worldwide, with smart and sustainability concepts, reflect almost mutual goals. It includes improving and providing the essential life services for all people efficiently while depending on sustainable, clean, and renewable energy with considerations of different economic, educational, health, social and environmental aspects in the city. In this research, a cost analysis process has been implemented to ease the implementation and resource utilization of smart and sustainable cities in Africa. The challenges and difficulties of those implementations are summarized.
\end{abstract}

Keywords-Smart cities; sustainable energy; renewable energy; internet of things; artificial intelligence

\section{INTRODUCTION}

Now-a-days, over three-quarters of the world's population lives in urban areas. It is noticed that the population growth in urban areas is higher than in rural areas. As such, cities are struggling with an overpopulation crisis triggering a shortage in capital resulting in issues across the society due to social and economic imbalance [1]. As technology is evolving, the concept of developing smart communities is becoming more desirable as the use of technologies like Artificial Intelligence (AI) and the Internet of Things (IoT) can help in solving a variety of problems in coexisting societies. For instance, IoT provides new ways for cities to utilize data to control traffic, reduce emissions, and allow better resources to provide people with a safe and clean smart environment. Smartness is a dynamic term that can be expressed as 'green technology.' The term "Smart City" is not just referring to a digital city; it also highlights the need for talented people and residents who are attentive to the priorities of having a smart, prosperous, and resilient city. It also refers to combining intelligence, political strategy, and infrastructure to create holistic urban services. Several aspects can aid in developing a Smart City, some of these aspects are: "Smart Mobility", "Smart Living", "Smart Economy" and many more that, when combined and strategized, can translate the practical meaning of having environmentally friendly, sustainable and smart city [2]. In general, no definitive or conclusive method can determine whether a city is smart or not. The significant primary definition relies on Information and Communication Technology (ICT) and the advanced immerging technologies like AI, IoT, etc.

On the other hand, implementing these technologies in underdeveloped countries is heading towards urbanization and industrialization. This implementation requires an understanding of smart city elements and how they are applied across various industries in the cities. This paper introduces a proposed framework and architecture in underdeveloped countries that can emphasize the use of new technologies and their performance to improve the quality of life in these inhabitants.

\section{LITERATURE REVIEW}

During the 2000s, cities worldwide radically changed, where the concentration turned to the vast development in digital technologies, knowledge, and the increase in environmental awareness and concern. Along with this development, new concept and model for the cities have been introduced. Over the last decades, these connected issues related to digital development started to initiate a new heading towards Smart Sustainable Cities.

According to [2], smart cities arise due to the intelligent use of technologies in different ar, such as the education field, health sector, transportation, and energy use.

Sustainability and sustainable city's urban development concept brings awareness of the production and use of available resources required in industrial areas, transportation, education, health, business, and investments.

Sustainable urban concept collaborates in increasing environmental awareness in naturally available resources in smart cities [3].

The author in [4] demonstrates that evaluating a smart city should be based on different factors like encompassing sustainability and quality of life and the collaboration of technological elements.

The concept of sustainable cities became popular in the 1990s [5]. It refers to the relationship between the conversion of resources exploitation to be consistent with the present and future requirements and the development of countries' economic and environmental sustainability aspects. 
Considering all the aspects, sustainable urban development can be defined as the combination of urban modernization to be smart with the use and protection of available sustainable resources.

The energy system for smart cities requires a significant share of renewable energy in the different aspects of the city. The energy system becomes more diverse, and it could be integrated into other areas with a crucial impact on the cities' development process.

There are several examples of smart and sustainable cities worldwide on different continents, as illustrated in Fig. 1 [6].

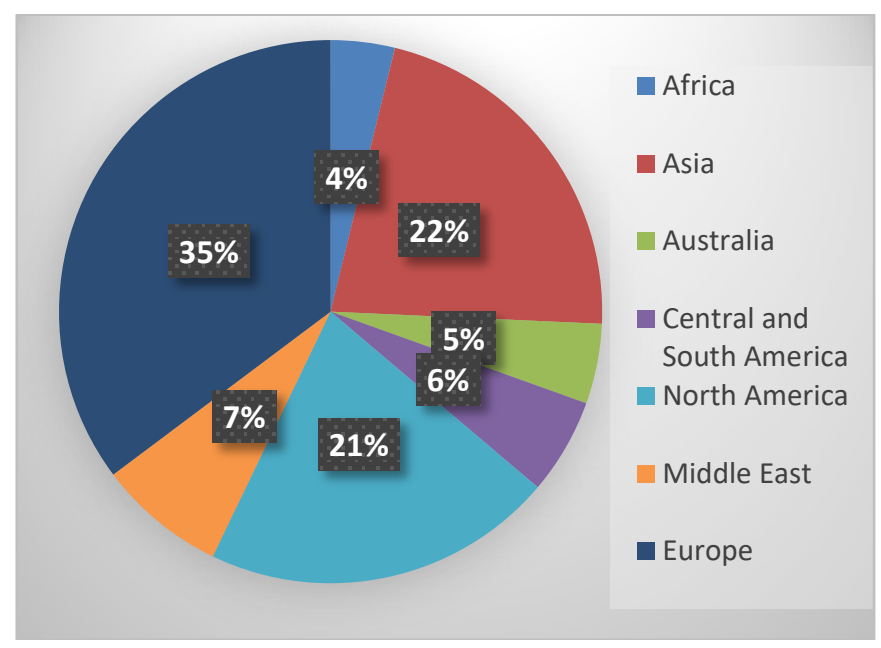

Fig. 1. The Total Sustainable and Smart Cities from Arcadis's.

Although Europe seems to lead the transformation of traditional cities to smart and sustainable cities, around $35 \%$ of the total cities engaged in sustainable and smart cities, $65 \%$ of the cities are moving forward steps to convoy the technology advancement and development. For example, a city like Dubai in the Middle East has a problem with the dramatic increase of the population, leading to a significant increase in environmental pollution. That is why Dubai is integrating an energy strategy action plan to depend on renewable energy and reduce energy demand and waste by $30 \%$ by 2030 . But what about the underdeveloped countries in Asia and Africa?. Do they have the ability to be transformed into smart cities? Could technological advancement provide optimal solutions to develop the cities' urban?. Do underdeveloped countries modernize their infrastructure and work based on an intelligent system?.

Building cities' innovative transformation requires applying the most effective, advanced, and developed information and communication technologies. In addition, artificial intelligence and the internet of things are also needed. The underdeveloped overpopulated countries have significant challenges when providing innovative transformation technologies.

A future smart city in the population urban in India is dramatically increasing. Around $50 \%$ of the population is expected to be in cities by 2030. This has a significant challenge for the government because of the wasted resources and the weak infrastructure. Based on global studies in [7], one in eight people lives in slums, while in India, one in six people live in slums where they lack access to safe drinking water, food, and homes. The Indian government aims to build 100 smart cities to provide essential services for inhabitants.

Moreover, many cities worldwide cannot supply the city's infrastructure with artificial intelligence and internet of things technologies. The cities aim to be innovative by providing essential services to the people depending on the available resources.

\section{MATERIAL AND METHODS}

Building smart and sustainable cities in underdeveloped countries require significant effort to extract and set a strategic plan for efficient use of available resources so that these resources can be used to develop intelligent systems that provide the essential services for people.

The sustainable resources are different in each country. For example, Africa holds 65 percent of the world's arable land, and over 70 percent of people depend on forests and woodlands. Thus Africa can use the wood with the help of solar energy as a renewable resource to build a sustainable and intelligent system. Examples of countries in Africa are Egypt and Sudan, located geographically on the AL-Nile River, which is the longest river in Africa. It could be an efficient resource to transform the cities to be smart.

Several countries in Africa lack electricity and internet services, and electricity is only provided for essential life services. Thus those countries cannot provide electrical energy to build intelligent systems or implement Internet of things technologies in the cities, as using these technologies requires a considerable budget. These countries can benefit from utilizing their different available resources to provide power for intelligent systems.

Let's set one of Egypt's cities as an intelligent city target. Egypt's population is over 100 million in 2020, where this considerable population percentage indicates the availability of various resources, a high ratio of traffic jams and accidents exists. Taking these indications, Egypt can utilize its resources to build a smart city efficiently.

For example, Egypt can utilize the water in the Al-Neil River to generate electrical energy. The requirements are a hydraulic turbine to convert flowing water into mechanical energy and a hydroelectric generator to convert the mechanical energy into electrical energy. Still, the pressure on the available water in the Al-Neil river is severed, that's why we need to utilize more resources to produce electricity. Now the question is, how can Egyptian cities become smarter with the help of the population?. The human body contains a massive quantity of energy. This energy works as a fuel for our everyday activities, but how can we generate electrical energy from the human body's movement?. The movement of human bodies generates kinetic energy that can be converted to power that can be later used to power electrical devices. The conversion of energy can be achieved via using piezoelectric sensors, electromagnetic, and electrostatic effects [8], thus adding these sensors in different ways to crowded places like streets, airports, malls, gyms, hospitals, schools, etc., can help in producing a sufficient amount of electricity. 
Moreover, solar energy cannot be ignored where it is proofed that the sun is a powerful, sustainable resource to generate power.

Integrating Internet-of-things and artificial intelligence technologies in cities means that the city infrastructure, including many different objects, will be connected. Artificial and machine learning techniques, including advanced sensors and controllers, are utilized in smart cities to create smart and connected buildings, autonomous vehicles, connected vehicles, smart education, smart health framework, and smart industries [9].

\section{PROPOSED FrAmEWORK FOR SMART AND SUSTAINABLE CITY}

\section{A. Smart and Sustainable Transportation System}

The intelligent transportation system in smart cities focuses on autonomous vehicles and connected vehicles that are extensive research. Many big companies built autonomous cars with different features and implemented advanced technologies. Autonomous vehicles have many significant features, such as mobility for disabled and older people to drive safely for long distances. Also, autonomous vehicles are charged electrically, which makes them eco-friendly. Accordingly, implementing an innovative, sustainable, and connected transportation system requires strong internet connections and sufficient electrical energy to be charged. Thus, sustainable resources play a vital role in converting the transportation system to a smart system. But here, two questions arise, how to generate electricity to charge the cars and power the internet connectivity? And how to implement an intelligent transportation system in Egypt?

There are many ways to charge cars and build a connected transportation system. Let us assume that all the vehicles in Egypt, whether public or private cars, taxis, or buses, are transformed into smart autonomous and electrical vehicles. They can be charged by adding a solar panel above the vehicle connected to the battery. It can help in reducing the need to set it in an electrical charging station. Still, we need to provide different options for charging, for example, adding a piezoelectric sensor which is a sensor that converts the pressure of the cars on the street to electrical energy. This electrical energy can be consumed in recharging the electric vehicles, turning street lights on or supplying the internet service provider to strengthen internet connectivity. Additionally, the connectivity between vehicles that are usually implemented via the internet connection, the connection method could be changed by making the vehicles that are close to each other for a specific distance connected, and they can communicate with each other via Bluetooth connectivity. The connected vehicles can communicate in case of an emergency situation, car accidents, bad weather conditions, or any different unexpected situation. In addition, sharing between vehicles can help exchange information about the other vehicle positions, speeds, routes, stopping, and decided to change lanes. It can be implemented using advanced machine learning algorithms and the internet of things technologies. Still, to ensure the efficiency of the connectivity, the communication also could be implemented through a mobile application installed in each driver phone; in this case, the energy consumption to provide robust internet connectivity is reduced [10].

\section{B. Smart Connected and Sustainable Infrastructure}

Smart and connected buildings are a new component introduced in smart cities where smart buildings contain many advanced and various embedded devices for proper control. Smart building concept means providing a safe and comfortable environment for people. Thus smart buildings will have different components and objects that maintain the comfort level for people who require less time and effort, including efficient and interconnected heat, ventilation, and cooling systems for individual floors in the buildings or other areas in the building and the smart metering of electricity, gas, and water, occupancy monitoring systems and hybrid vehicle charging technology.

Moreover, automation and wireless technology are essential in smart buildings. People communicate with the building's components like doors, windows, lights, machines via different control options like mobile application, voice, and radio frequency identification, which can help in reducing the percentage of diseases that could be transmitted by touch.

A question arises here, how to supply these buildings with electricity and internet connectivity consistently?

According to previous research [11], global energy consumption in commercial and residential buildings has steadily increased between $20 \%$ and $40 \%$ in developed countries. Moreover, as the population grows, the higher the percentage of power consumption, governments, especially in undeveloped countries, should follow different strategies to provide electrical energy for buildings.

There are many different ways for generating consistently electrical energy in buildings, such as adding solar panels on the roof of the facility connected with batteries to be used later. In addition, depending on the kinetic energy generated from human body movement to be converted to electrical energy could be a good solution. Generating electrical energy from a human could be implemented in several ways. For example, they are adding a piezoelectric sensor in the shoes, where shoes now can convert the kinetic energy into electrical energy stored in a portable battery to be used later in charging the smart devices like phones or watches. Accordingly, this will reduce the power consumptions used in charging smart devices. Furthermore, a piezoelectric sensor could be added to mats in the entrance and the exit buildings where this generated energy could be used later in controlling the intelligent doors, windows, lights, and so on.

In addition, some buildings can specify space for people to do their sports. This space can be utilized sufficiently if a piezoelectric sensor provided the specific space to produce electricity while people are running or using doing their daily workouts. Also, there is an additional energy source, where a generator can be connected to bicycles to gain benefits from the mechanical energy generated by humans to be converted to electrical energy that can be used in the smart buildings [12]. Moreover, a simple, sustainable, intelligent system could be implemented in Egypt, connecting solar panels and light sensors to the streets' light. Thus the light will be charged from 
the solar panels, and it will be turned on and off based on the sunlight availability so that the lights will be off during the morning and afternoon time, and it will be on at the evening time.

All these options can be implemented to power the intelligent systems that will control the essential services in the building, whether the building is a mall, gym, park, school, hospital, or home.

\section{Smart and Sustainable Health Framework}

Smart hospitals are applying extensive use of new intelligent systems and technologies to improve healthcare quality at less cost.

Concentrating on and implementing new technologies like artificial intelligence, robotics, 3d printing, augmented and virtual reality, and telemedicine plays a vital role in immediate requirements like reducing cost and high efficiency and longterm goals like greater precisions, fewer errors, and better outcomes.

The healthcare framework is changing due to the increasing number of today's patients because of vital viruses who require healthcare services.

The change in healthcare framework to be smart includes embedding many new technologies into hospitals' design and operations to improve patients' experience, embedding new technologies to improve healthcare, and create an interconnected system between all hospitals. A question arises here: how to integrate new technologies in Egypt where electricity is not consistently available, thus using renewable and sustainable resources and green practices could be challenging.

Several suggestions that could convert the hospital nowadays in Egypt to smart and sustainable hospitals such as hospitals can implement the same intelligent system in smart homes: the HVAC system and patient record to control room's temperature. When the room in the hospital is empty, the system is adjusted to the minimum ventilation settings. When the patient is in the room, he can control the temperature via remote control or voice. Although hospitals' HVAC systems help in electricity consumption reduction, at the same time, this system helps in reducing the injuries percentage by patients who are in need to leave the bed to adjust the room temperature.

Moreover, as the hospitals and medical centers are usually crowded places, thus converting the kinetic energy of people who are entering the hospitals to electrical energy could help in reducing the electrical energy consumption in the hospitals. Moreover, hospital buildings can include the same feature as smart buildings, solar panels, fuel cells, and an underground water system.

But what about the intelligent healthcare system?. In addition to the use of generated electricity from different resources to power the smart devices used in intelligent systems, a part of the healthcare system can be converted to a virtual system and gain benefit from telemedicine technology, where there will be an artificial intelligence virtual health assistant persist in a mobile application that can talk and respond to people questions and situations, if it is a simple health problem that the virtual assistant could solve, then the problem could be easily solved. Otherwise, a human assistant will be presented to aid in suggesting the patient's problem. Furthermore, in medicine, artificial intelligence-based analytics for supporting the decision-making process is required, that is why an example of an artificially intelligent algorithm recently developed to rapidly detect Covid-19 by combining patient's chest scan with clinical information like age, blood report and contact information, the system can help in evaluating the infected patients [13]. Moreover, intelligent systems can assist in work management like scheduling and planning clinical staff working time and allowing the clerk desk laborers to reduce their intensive tasks by replacing their work with automation and artificial intelligence algorithms.

\section{Smart Education System}

Intelligent systems and the internet of things can provide significant communication between virtual and physical objects, thus implementing artificial intelligence and internet of things technologies in the education system plays an effective role in converting the traditional education systems into a smart system for both teaching and learning process.

Transforming the education system means integrating new technologies like artificial intelligence, simulation, and virtual and augmented reality. A smart education system enables customized learning, which means students get a learning plan based on their skills, strengths, and interests to upgrade students' learning capacity for knowledge. Smart learning system includes many software and hardware tool like online resources, analytical tools, smart devices, interactive whiteboard, e-books, and e-bag.

Additionally, a smart education framework means converting the learning environment to be smart, including classrooms, schools, universities, etc.

The author in [14] explains some applied examples of smart learning, such as smart classrooms, including electronic and smart devices like internet connectivity, smart whiteboard, tablets, e-books, and a projector. While smart laboratories should have special smart devices like virtual reality glasses and computers to simulate different subject topics and requirements, for example, simulating the global wars in history subject could be in a very interesting way in virtual reality simulator, or simulating human heart with all its parts using augmented reality. Also, in university, virtual reality and simulation can positively affect university students by converting all the theory parts to either simulated or practically applied in labs which assist in a better understanding of their major. Using these technologies in schools, students will be more satisfied with understanding lectures, doing presentations, and conversing with others. At the same time, teachers will be more confident and comfortable while giving the lessons and explaining the new concepts and ideas. Moreover, some applications transform the education system to smart such as: 
- Smart surveillance system: this system could be applied in schools or universities to collect information from daily classes by using a camera, microphone and artificial intelligence algorithm to extract the information from the retrieved records from cameras to be then stored in the cloud for future use and for absents students to attend the classes through his/her smart device.

- Smart attendance system: collecting the attendance information in school or university requires time, especially in big classrooms or universities, that is why a smart attendance was developed that work based on RFID (Radio Frequency Identification) system where an RFID reader will be in each classroom and an RFID card with each student, thus the students need to pass their cards on the RFID reader to be recorded as attending. Also, the attendance system can be implemented through NFC (Near Field Communication), where NFC will be embedded in each student's phone, and an NFC scanner is placed in each classroom. Thus the attendance is recorded by scanning the NFC in each phone to store the information later in a specific server.

Implementing these systems requires a consistent amount of electricity to power the systems. The school building can be provided with the same sustainable techniques and ways to use smart buildings like solar panels and human energy harvesting. Converting students' energy to electricity would generate a good amount of energy.

After the text edit has been completed, the paper is ready for the template. Duplicate the template file by using the Save As command and use the naming convention prescribed by your conference for the name of your paper. In this newly created file, highlight all of the contents and import your prepared text file. You are now ready to style your paper; use the scroll-down window on the MS Word Formatting toolbar's left.

\section{E. Smart Industry}

The industry sector in smart cities had an incredible revolution that made changes in manufacturing. Many new concepts have been introduced, such as industry 4.0 , which is the outcome of the shift of digitalization and automation in the manufactory sector. These concepts enabled self-optimization, cognition, and customization in the industry field, where communication with machines and computers is possible. It is implemented through the internet of things, machine learning, autonomous robots, the internet of services, big data management, and cloud computing.

The internet of things is an essential component in the industry field in smart cities. It enables systems connectivity, communication between different objects and machines and can be accomplished by controlling other parts in the industry like controlling temperature, light, devices, and remote control. In contrast, the internet of service (IoS) is presented as the "service vendors" which provide digital services through the internet according to the business type.
Moreover, big data management and analysis play a vital role in the revolution of the industry sector, where a vast amount of data and information are produced daily in the industry. Big data management and analysis are used through utilizing new technologies to make analyses that can be further used in the development process of the produced products.

Furthermore, robotics automation is the technology that has dramatically changed the world, where robots, machines, and automation reduced the employers' number, effort, and time with high proficiency and accuracy.

On the other hand, developing the industry field in Egypt with implementing these technologies requires a good amount of energy consistently. It is something that is not easy to be provided. That is why a new adaptive way of generating electricity is required, as solar panels or human energy harvesting is not enough to power on giant machines during the manufacturing process!

Commonly, in countries worldwide, the manufacturers are built far away from the residential areas. Thus in Egypt, the populations are the most near to Al-Nile river where the government is producing the majority of electrical power from the water of Al-Neil, but how the manufactories will be provided with a sustainable resource of electricity far away from the Al-Nile river?

As the significant area of Egypt is desert, a good amount of electricity could be produced from the sand. According to [15], and is used to generate and store energy in Italy, where the plant is supposed to be as a concentrated solar panel that focuses sunlight on heating sound. The hot sand produces around 500 kilowatts of energy with one turbine added which is enough to power a small village, and more turbines can be added to increase the power, in this case, a reduction is made in the unsustainable electricity consumption, where the city can develop the smart industry sector without huge consumption of electricity.

\section{RESULTS AND DISCUSSIONS}

After introducing the five essential parts of smart cities and the way, they are developed in underdeveloped countries, and create a relationship between developing these parts and sustainability. The author in [16] explains the smart city architecture as illustrated in Fig. 2.

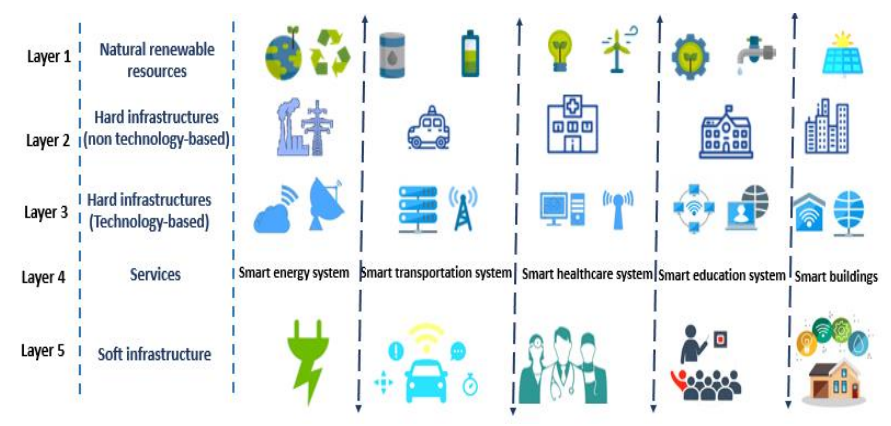

Fig. 2. The Smart City Architecture. 
The smart city architecture includes four different layers:

Layer 1: Natural resources in the environment include the renewable resources available in the city, such as water, sunlight, fuel, and wind.

Layer 2: Physical infrastructures and services that are existed in the city. These physical infrastructures do not depend entirely on technology in their daily operations, such as transportation modes like cars, trains and buses or buildings, schools, offices, hospitals, etc.

Layer 3: Physical infrastructures and services that are technology-based and depend on technology to perform daily operations, such as communication networks, sensors, security cameras, etc.

Layer 4: The new smart services and applications developed based on the latest and advanced technologies and are used daily, such as smart transportation systems, smart health systems, smart energy systems, etc.

Layer 5: Soft infrastructures are individuals and communities living in urban areas such as stakeholders, companies, and other people utilizing smart applications and services.

Developing smart cities and implementing the smart city architecture with smart applications and services require performing a cost-benefit analysis (CBA) that is used to estimate the value of the cost and the benefits of developing and implementing a project. We can finalize whether the project is worthwhile or not.

Cost-benefit analysis is a systematic quantitative method of assessing the desirability of new projects or policies that are important for the long term and might have future effects on society.

The cost-benefit analysis is essential for stakeholders as it provides a comprehensive overview of the cost and benefit of a project. The cost-benefit research includes the following:

\section{A. Project Lifetime}

The project lifetime varies for different projects and depends on whether the project is private or public. The project's lifetime usually changes if the project is continually improved and modified, such as cars, buildings, highways, etc.

When the cost-benefit analysis is applied to investments in transportation systems, the project lifetime assumptions should consider that the transportation system project should have an infinite lifetime [17].

There are some examples shown in Table I of public projects' lifetime.

As illustrated in Table I, the energy and environment sectors have more life than the industry sector projects. The energy and environment sectors depend on renewable resources; thus, it can last for a long time, but for the industries that rely on systems or machines like telecommunication and industry sectors, the improvements for the project can aid in increasing the project lifetime limited period.
Thus, we need to consider the lifetime for different sectors for implementing a smart transportation system as the transportation system is related to the seven sectors mentioned in Table I.

\section{B. Cost-Benefit Analysis Process}

The cost-benefit analysis concept is used to evaluate the efficiency of the proposed solutions within the smart cities. The CBA is a general platform that constructs many questions and answers to provide the basic information for the construction and formulation of smart solutions. Fig. 3 illustrates the primary analytical framework of a simple CBA model designed to determine the efficiency of the solutions.

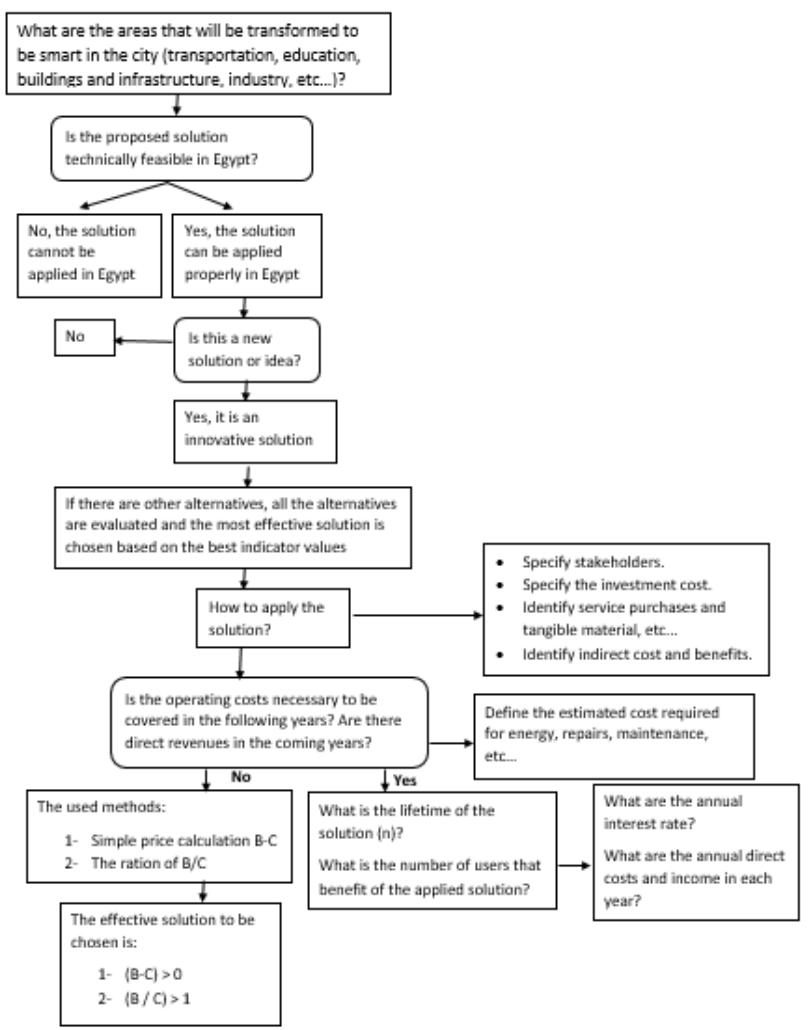

Fig. 3. The Primary Analytical Framework of Cost-benefit Analysis for a Smart Solution in a Smart City.

TABLE I. THE PROJECT LIFETIME FOR DIFFERENT INFRASTRUCTURE SECTORS

\begin{tabular}{|l|l|}
\hline Infrastructure sector & Project lifetime (years) \\
\hline Energy & 25 \\
\hline Environment & 30 \\
\hline Railways & 30 \\
\hline Roads & 25 \\
\hline Ports and airports & 25 \\
\hline Telecommunications & 15 \\
\hline Industry & 10 \\
\hline
\end{tabular}


Using the primary analysis of the CBA, several questions arise such as:

1) What are the areas that the smart solutions will be applied in?

2) Is the solutions technical could be applied in Egypt?

3) Are there any other alternatives for the solution to be considered?

4) What are the possible ways of implementing the solution? Specify all the input requirements, costs, and stakeholders.

5) Will it be necessary to cover the operating costs in the upcoming years? And what are the direct benefits in the coming years? If yes, what are the lifetime (years) of the solution and the number of users that the services will concern?

6) What are the annual interest rate and the annual indirect, direct cost yearly?

For example, let us suppose that a smart transportation system will be applied in a smart city in Egypt; what are the cost and benefits of the project, and how to evaluate the efficiency of the project?

According to [18], Egypt is planning to build smart cities on the cusp of the nation's sustainable development strategy in 2030.

Suppose we suppose that a smart city will be placed in Great Cairo city, the largest urban city in Africa, the Middle East, and the Arab world. A plan has been set to develop the urban in the city where there is a study performed to illustrate the major indicators of the Greater Cairo Region in 2022, shown in Table II.

TABLE II. MAJOR INDICATORS OF GREATER CAIRO REGION IN 2022

\begin{tabular}{|l|l|}
\hline Socio-Economic Indicators & $\mathbf{2 0 2 2}$ \\
\hline Population (Million) & 20.7 \\
\hline Motorization (Million Vehicles) & 2.50 \\
\hline Trip Generation (Million Trips) & 25.1 \\
\hline
\end{tabular}

The development plan includes:

- Improvement in the road network and urban expressway network.

- For the public transport: extending the metro lines, satellite cities corridors, super tram system, network improvements, and optimized route structure.

To evaluate the development plan, the variables in implementing the project should be specified: the cost and the benefits of a smart transportation system.

The cost of the smart transportation system includes the following:

1) Capital cost: the capital cost means the initial cost of planning, designing, and implementing a project. The capital cost includes the design cost for roads, cars and systems, construction cost, electrical and electronic engineering cost, programmer cost, labor cost, and equipment purchasing cost in the smart transportation system.

2) Maintenance cost: Maintaining the technical parts for proper working conditions is required.

3) Operating cost: it is the cost of the advertisements, rent payments, and license fees needed annually.

4) Other costs: in addition to the operation and maintenance costs, more costs are to be considered. Specifically, there is additional cost related to smart solutions, technologies, cybersecurity, control and intelligent systems, and power generation systems.

That means the total cost of a smart transportation system in Egypt $=C_{\text {capital }}+C_{\text {maintainance }}+C_{\text {other }}$

The benefit is the revenue of the investments in a project, many benefits come from the smart transportation system in a smart city such as:

Travel time and cost reduction: The goal of any project is to gain the maximum benefit and pay less cost and efforts, thus the smart transportation system help in reducing the cost of traveling by lowering the payment amount for fuel consumptions, at the same time, the time of travel is reduced due to the connected cars' systems that are designed to reduce the traffic congestion time and reduce the traffic accidents as much as possible. According to the cost-benefit analysis, the financial value of the travel time reduction for different transportation modes can be expressed as:

$V_{\text {Time }}=\sum_{i}\left(\Delta t_{i} \times w_{\text {time } i}\right)$

Where $\Delta t_{i}$ is the reduction in the travel time of each mode $i$.

Fuel and energy consumption: The primary challenge of developing a smart city in Egypt is providing the required energy to power the proposed intelligent systems. Thus we want to generate the maximum amount of renewable energy and reduce the consumed amount of fuel which is something difficult to be implemented especially for the transportation systems that depends on fuel for its daily operation, but converting the transportation system in Egypt to be sustainable system and replacing the mechanical cars with smart electrical cars means the fuel consumptions should be reduced, especially if a renewable resources generate the electrical energy.

For the smart transportation systems, the annual cost of the reduction in energy and fuel consumption is illustrated in this equation:

$V_{\text {Fuel }}=\Delta G_{\text {Fuel }} x w_{\text {Fuel }}$

Where $\Delta G_{F u e l}$ is the amount reduced of fuel every year and the $w_{F u e l}$ is the average price of fuel.

Reduce the gas emission: According to [19] the annual percentage of the energy-related carbon emission will be $10 \%$ higher than the percentage of emissions in 2014, but with the advancement in hybrid and electrical cars, the percentage will be decreased in 2030, as there are more concerns about the energy efficiency spreads and carbon reduction policies. 
The author in [20] evaluates the development plan in the transportation system in Cairo by comparing cost-benefit analysis of the transportation system in 2001, committed project 2022, and the optimum result in 2022. It has been found that the development plan will help in recovering the average trip speed to around 18 kilometers per hour with the increase in the transport demand in 2022, with road congestion around 1.0. Moreover, the passenger of public transport in 2022 will be around 20.3 million per day compared to 18.2 million per day in 2001. In comparison, the carbon emission will be reduced by $15 \%$ compared to the percentage of emission in 2001.

The development plan and the CBA in Table III in Cairo transportation system does not cover the intelligent systems and the internet of things techniques and the smart energy generator systems, also the CBA ignores the future prices, population, requirements and improvements.

Where the smart and intelligent transportation system determines to install advanced and modern cameras, sensors, solar panels and internet connectivity.

Table IV shows the actual price of sensors and cameras used in smart cars and smart transportation systems collected from different online shops.

To reduce the cost of implementing an intelligent transportation system in Egypt, we must consider that not all the citizens can replace their car with a new smart electrical car which cost around 10,000 USD to 20,000 USD for small cars such as TESLA cars according to their prices online, but if the government announces clearly that, all citizens who live or work in new Cairo smart city must drive an electrical smart car, the citizens will either buy a new smart electrical car or transform their cars by installing an electric motor which cost around 6000 USD and adding large batteries about 1000 USD - 3000 USD, then installing sensors and cameras are required to be a smart car as well which costs around 1000 USD to 1500 USD based on the prices in Table III, thus the cost of transforming the cars or buying a new smart electrical car will cost almost the same.

Thus, based on the number of motorization in new Cairo in Table II, and based on the cost of transforming or buying new smart electrical cars, the cost of the system will be around 26 billion dollars, which is the capital cost for an intelligent transportation system in the high population new Cairo city. Also, the development of the city cost will be added to the cost of the intelligent transportation system according to Table III is 59.8 billion.

Furthermore, the cost of renewable energy resources which will be used in the cars, roads and in generating electricity from water or wind to be used later in charging the electrical cars such as the solar panels, wind turbine generator, Hydro generators and piezo electric sensor are shown in Table V.

According to Tables III, IV and V, the capital cost of developing smart sustainable transportation system in new Cairo will exceed 100 billion USD. Comparing the capital cost of the intelligent transportation system in Egypt 2022 with the capital cost for a smart transportation system in United States with lower population in Newark city 2015 [21] which is a developed city, where the capital cost was 100 billion without depending on the sustainable and smart energy systems, thus we can figure out that, the result of the capital cost calculation in Egypt is reliable.

TABLE III. The COST ANALYSIS FOR THE DEVElopMENT Plan OF GREATER CAIRO

\begin{tabular}{|c|c|c|c|}
\hline Scenario & $\begin{array}{l}\text { The } \\
\text { transporta } \\
\text { tion system } \\
\text { in } 2001\end{array}$ & $\begin{array}{l}\text { Committed } \\
\text { transportation } \\
\text { system project } \\
2022\end{array}$ & $\begin{array}{l}\text { The optimum } \\
\text { scenario of the } \\
\text { developed } \\
\text { transportation } \\
\text { system }\end{array}$ \\
\hline Cost (LE billion) & - & 18.2 & 59.8 \\
\hline $\begin{array}{l}\text { Benefit-Cost } \\
\text { Ratio }\end{array}$ & - & - & 1.77 \\
\hline $\begin{array}{l}\text { Trip speed } \\
(\mathrm{Km} / \mathrm{hr})\end{array}$ & 19.0 & 11.6 & 18.0 \\
\hline $\begin{array}{l}\text { Sharing } \\
\text { percentage of } \\
\text { public transport }\end{array}$ & 70.9 & 61.7 & 57.9 \\
\hline $\begin{array}{l}\text { Number of public } \\
\text { transport } \\
\text { passengers } \\
\text { (million / day) }\end{array}$ & 13.3 & 18.2 & 20.3 \\
\hline $\begin{array}{l}\text { Vehicle- } \\
\text { kilometer ( } \\
\text { million pcu- } \\
\text { km/day) }\end{array}$ & 62.8 & 127.3 & 139.7 \\
\hline $\begin{array}{l}\text { Volume } \\
\text { /Capacity Ratio }\end{array}$ & 0.74 & 1.11 & 1.00 \\
\hline $\begin{array}{l}\text { Population within } \\
800 \mathrm{~m} \text { of Public } \\
\text { transport } \\
\text { (million) }\end{array}$ & 2.04 & 3.09 & 8.20 \\
\hline $\begin{array}{l}\text { Employment } \\
\text { within } 800 \mathrm{~m} \text { of } \\
\text { public transport } \\
\text { (million) }\end{array}$ & 1.11 & 1.70 & 4.20 \\
\hline $\begin{array}{l}\text { Students within } \\
800 \mathrm{~m} \text { of public } \\
\text { transport } \\
\text { (million) }\end{array}$ & 0.74 & 1.08 & 2.70 \\
\hline $\begin{array}{l}\text { Carbon emission } \\
\text { (million ton) }\end{array}$ & 12.2 & 15.9 & 13.6 \\
\hline
\end{tabular}

TABLE IV. THE ACTUAL PRICE OF SENSORS AND CAMERAS USED IN SMART CARS AND SMART TRANSPORTATION SYSTEMS

\begin{tabular}{|l|l|}
\hline Sensors & Actual price \\
\hline Ultrasonic sensor $\mathrm{x} 4$ & 16 USD to 40 USD \\
\hline Automotive mono-camera & 100 USD to 1000 USD \\
\hline
\end{tabular}

TABLE V. PRICES OF RENEWABLE POWER GENERATORS

\begin{tabular}{|l|l|}
\hline Power generators & Actual price \\
\hline Solar panels & 200 USD to 300 USD \\
\hline Hydroelectric generator & 3,000 USD to 80,000 USD \\
\hline Wind turbine generator & 2,000 USD to 4,000 USD \\
\hline Piezo electric sensor & 40 USD to 60 USD \\
\hline
\end{tabular}




\section{Challenges For SMART AND Sustainable Cities}

It is widely known that to implement smart city projects, we have to combine information technology with internetconnected technologies. This case is especially true for underdeveloped countries that this paper focuses on. Smart city projects combine several technologies and applications that help improve management like waste management and smart grids [22]. Suppose smart cities became the 'modern standard'. In that case, decision-makers might need to navigate through different fields like connectivity, infrastructure, data, and security as cost and development are challenging. With technology and standards continually changing and quickly evolving, municipalities will need to avoid being trapped in using integrated solutions from a single provider, which ultimately leads to information and resources silos, making it even harder to exchange data with other municipalities. Thus, understanding that building a smart city goes beyond automating internal systems and introducing new applications. Implementing the concept of smart and sustainable cities in a country comes with various obstacles, including specific city criteria, variation of technologies, connecting infrastructures and conserving resources.

\section{A. Infrastructure Modernization}

The term "city infrastructure" includes housing, sanitation, water, and sewer supply, waste management, transport, energy supply, and distribution. The difference between smart and conventional infrastructure is the ability of smart infrastructure to adapt intelligently to changes in the environment without disregarding user needs to achieve improved performance. Smart city infrastructure provides the basis for all smart city themes, including transportation, economy, government, environment, and citizens. The smart infrastructure design depends on how modernized or developed a country is.

For a city in an underdeveloped country, developing a smart infrastructure will require considering cost, space and other factors to promote better management and development of resources. For example, to create smart transportation infrastructure, a massive amount of data must be gathered to redesign the transportation network and build new applications. Thus, requiring a large amount of capital from a country that is moving to develop and could not afford high costs. These countries can maintain the city's current infrastructure and focus on optimizing existing infrastructure resources and monitor performance. For example, establishing renewable energy infrastructure to the existing one to manage natural resources like water and utilize wind and solar energy to improve waste management. However, in both developing and developed countries, the primary reason behind smart infrastructure applications is adapting to society's demands for sustainable growth. Table VI summarizes some of the sustainable challenges and smart infrastructure solutions proposed for modernization.

\section{B. Security and Privacy}

Data is a core component of Smart Cities. Sensor networks, smart meters, cell phones and IoT devices all produce massive quantities of data. These generated data could be converted by the city government to create new insights that could be monetized and shared with various stakeholders. Smart urban infrastructure components pose risks and safety issues, as smart infrastructure may be vulnerable to hacking and unauthorized access. The problem of protecting people's privacy is also a significant concern in this regard. Many of the widely mentioned risks include stealing users' data and implementing ransomware. Of course, the hazard level grows as IoT systems become more controllable and more autonomous. In these latter situations, cybercriminals can exploit vulnerabilities to remotely control IoT devices to alter sensor or system actions, sabotage these devices, or even cause physical damage to the surrounding environment [23]. Such activities result in cyber hackers having more access to confidential data that expose customer behavior trends. We might also see more mobile device robberies, as more can now have physical access to homes and workplaces. As IoT ecosystems are built and often include several stakeholders and vendors, and customers, it is necessary to be aware of possible compliance problems if either confidential data is hacked or these sensors and devices are themselves regulated by cyber criminals [23]. Organizations and municipalities must identify and explicitly recognize each other's positions, obligations, and standards in terms of data protection and even in the event of data breaches within IoT ecosystems. To expand current cybersecurity strategies, a risk control policy should be developed so that both organizations in the public sector obtaining these systems and in the private sector developing them will need to be take into consideration the ramification of developing and obtaining these technologies and the data protection and AI threats that will need to be resolved by effective governance steps [24].

TABLE VI. CHALLENGES WITH INFRASTRUCTURE MODERNIZATION

\begin{tabular}{|l|l|l|}
\hline $\begin{array}{l}\text { Sustainable } \\
\text { Challenges }\end{array}$ & $\begin{array}{l}\text { Proposed Smart } \\
\text { Infrastructure }\end{array}$ & Description \\
\hline $\begin{array}{l}\text { Improving } \\
\text { Energy } \\
\text { infrastructure }\end{array}$ & Smart Meter & $\begin{array}{l}\text { Monitor behavior regarding } \\
\text { electric energy and measure } \\
\text { consumption }\end{array}$ \\
\cline { 2 - 3 } & Smart Grids & $\begin{array}{l}\text { Manage variable renewable } \\
\text { power supply }\end{array}$ \\
\hline $\begin{array}{l}\text { Affordable, } \\
\text { good quality } \\
\text { connectivity }\end{array}$ & High-Speed Internet & $\begin{array}{l}\text { Cellular and Low Power Wide } \\
\text { Area (LPWA) technologies }\end{array}$ \\
\hline $\begin{array}{l}\text { Environmental } \\
\text { Performance }\end{array}$ & $\begin{array}{l}\text { Environment Sensor } \\
\text { Network }\end{array}$ & $\begin{array}{l}\text { Collect data regarding } \\
\text { environmental condition and } \\
\text { level of pollutants }\end{array}$ \\
\hline $\begin{array}{l}\text { Health and } \\
\text { Education }\end{array}$ & $\begin{array}{l}\text { Telemedicine, Remote } \\
\text { healthcare, and Online } \\
\text { Education }\end{array}$ & $\begin{array}{l}\text { Services and products to access } \\
\text { education and health services } \\
\text { remotely }\end{array}$ \\
\hline
\end{tabular}

\section{Internet Connectivity}

Introducing smart city technologies requires a robust and efficient broadband network. This shows the need to continue bridging the digital gap to utilize and take advantage of smart applications (apps). Mobile broadband networks play a key role in a shortage of fixed networks. Smartphones revolutionized smart cities as several "apps" were developed to ease users in handling several facilities like road and transportations, health and fitness, and electricity and water.

Due to increased sensor and data used, robust and high connectivity is needed to maintain and accommodate it. This is where $5 \mathrm{G}$ shines and provides the essential structure, capability 
and service that provide cases underpinned by technological features like high bandwidth, absolute reliability, wide availability, and responsive connectivity. Such utilization of technology is limited to a city's budget, which is the case with underdeveloped countries [25].

\section{Funding and Financing}

Conceptualizing smart cities provides a digital layer on any capital asset, opening the way to unparalleled possibilities, technological improvements, and increased profitability. One significant factor that can make a smart city design productive is the consistent path to steady revenue (its revenue model). A reliable funding source is particularly important if the project is pursuing private financing. When planning the project, it is important to be mindful of the difference between the terms "Financing" and "Funding". The government provides particular money for specific reasons with free charges and no interests in terms of funding. In comparison, the term financing refers to financial/private institutes that grant a project a certain amount of "funding" as equity to be returned later with interests. For underdeveloped countries in Africa, it is crucial to think about revenue and cash flow, how funds can be recovered from the overall revenue, the value created, and how to monetize it. That's why it is important to strategize a plan to secure funds and finances from different investors, as some might focus on infrastructures like roads and transportation while others might focus on different sectors and themes.

\section{E. Energy Management}

Cities that have high population densities in a country like Egypt generally require a huge power source. Once these cities are developed as smart cities, renewable energy resources will be integrated with the city's electrical infrastructure to support the economy and life-quality growth. Smart cities can help sustain energy and environmental challenges that produce a proportion of carbon emissions. It is generally known that cities play an increasingly decisive role in addressing climate and environmental challenges. Cities are naturally able to grow to face the world's many energy and environmental problems. Human and intellectual capital, along with economic and political influence, can fuel the increased use of renewable energy. The primary constraints that might be faced make these cities hubs for technical and social creativity to drive change globally. Energy and environmental considerations are key that drives (and limit) all facets of urban planning [26].

\section{CONCLUSION}

This research claim that implementing the smart city model could provide an opportunity for underdeveloped countries to handle the effects of rapid urbanization, including their economic and environmental implications and the decrease in quality of life. Achievement of sustainability and enhancement of quality of life in underdeveloped cities varies from one country to the other. According to the findings, no standard criteria determine a city's smartness, and analysis must be performed before settling on smart projects and systems. This research analyzed the cost and benefits of making New Cairo, Egypt into a smart city. Also, this research discussed how utilizing the rich resources in Africa and investing in smart technologies makes the underdeveloped countries across the continent leap urban revolution. We finalized that in smart city projects, sustainability becomes interwoven with various objectives and priorities, all of which interfere and influence each other, generating potential feedback loops and unforeseeable results.

\section{REFERENCES}

[1] B. O. Bureau, "Why we need smart cities," 19 February 2019.

[2] M. Deakin, "From intelligent to smart cities," Intelligent Buildings International, 2011.

[3] T. Yigitcanlar, "Smart cities: an effective urban development and management model?," Autralian planner, 2015.

[4] J. c.-L. a. J. M.-F. Marsal-Lluisa Marsal-Llacuna, "Lessons in urban monitoring taken from sustainable and livable cities to better address the smrt cities initiative," Technological Forecasting and Social Change, 2015.

[5] M. Roy, "planning for sustainable and urbanisation in fast growing cities: Mitigation and adaption issues addressed in Dhaka, Bangladesh," Habitat international, 2009.

[6] G. Match, "From Sustainable to Smart Cities," The Future of Modern Cities, 06 November 2018.

[7] S. Kumar, "Aimed at ending poverty, smart city project ends up hurting the poor itself," 26 December 2018.

[8] Q. H. J. W. Z. Z. \&. X. L. Keli Li, "Wearable energy harvesters generating electricity from low-frequency human limb movement," Microsystems \& Nanoengineering, 2018.

[9] J. M. G. G. H. N. M. A. Hossein Shahinzadeh, "IoT Architecture for Smart Grids," in International Conference on Protection and Automation of Power System (IPAPS), 2019.

[10] I. R. Pawl Gora, "Traffic models for self-driving connected cars," Elsevier, 2016

[11] J. C. LuisPérez-Lombard, "A review on buildings energy consumption information," ScienceDirect, 2008.

[12] E. Cosgrove, "Can you really power your home with a bicycle generator?," 4 September 2020.

[13] D. R. H. V. Kumar Chebrolu, "Smart use of artificial intelligence in health care," 22 October 2020

[14] D. Mohanty, "Smart learning Using IoT," International Research Journal of Engineering and Technology (IRJET), 06 June 2019.

[15] R. E. World, "Italian Company Uses Sun-Heated Sand to Produce Energy," 21 May 2015.

[16] Anthopoulos, "Understanding smart cities: A tool for smart government or an industrial Trick?," Springer, 2017.

[17] D. Lee Jr, "Fundamental of life-cycle analysis. Transportation research record," Journal of the transportation research board , 2002.

[18] A. G. o. b. o. U. N. I. C. -. Cairo, "Smart Cities: Egypt "Theory and Application - Towards an Egyptian Smart Cities Code"," 09 December 2019.

[19] ExxonMobil, "Innovating energy solutions: Research and development highlights," Energy and innovation, 2014.

[20] J. I. C. A. (JICA), "Public-private partnership for Cairo urban toll expressway network development," Katahire \& Engineers International, 2006.

[21] X. Xiong, "Cost-Benefit analysis of smart cities," Xiangyuan Xiong, 2018.

[22] N. A. a. K. Hasley, "Smart cities face challenges and opportunities," 25 July 2018.

[23] N. D. Evans, "The IoT meets the Internet of Behaviors | CIO," 2014 June 2014

[24] N. G. a. M. Sobiecki, "Artificial intelligence in smart cities," 10 August 2020.

[25] Telecoms, "the challenges of 5G and smart cities," 15 June 2020.

[26] P. L. Thiez, "Smart City: Energy Challenges Facing Sustainable Cities," 01 October 2018. 